Revista de Metalurgia 51(3)

July-September 2015, e049

ISSN-L: 0034-8570

doi: http://dx.doi.org/10.3989/revmetalm.049

\title{
Quenching simulation of steel grinding balls
}

\author{
Oscar Zapata-Hernández ${ }^{\mathrm{a}}$, Luis A. Reyes ${ }^{\mathrm{a}}$, Carlos Camurri ${ }^{\mathrm{b}}$, \\ Claudia Carrasco ${ }^{\mathrm{b}}$, Nelson F. Garza-Montes-de-Oca ${ }^{\mathrm{a}}$, Rafael Colás ${ }^{\mathrm{a}, \varpi}$ \\ ${ }^{a}$ Universidad Autónoma de Nuevo León, Facultad de Ingeniería Mecánica y Eléctrica, México \\ ${ }^{\mathrm{b}}$ Universidad de Concepción, Departamento de Ingeniería de Materiales, Chile \\ Corresponding author: colas.rafael@gmail.com
}

Submitted: 11 February 2014; Accepted: 2 June 2015; Available On-line: 14 September 2015

\begin{abstract}
The phase transformations of high carbon steel during quenching and equalizing were modelled using commercial computer packages based on the finite element method and the kinetic transformation of steel. The model was used to predict the temperature and microstructural changes taking place within balls of two different sizes that are used for grinding mineral ores. A good correlation between the temperatures measured by inserted thermocouples and those predicted by the model was obtained after modifying the thermal conductivity of the steel within the temperature domain at which mixed phases are present. The phase transformations predicted were confirmed by metallographic analyses.
\end{abstract}

KEYWORDS: Computer modelling; Heat treatment; Microstructure; Steel

Citation / Cómo citar este artículo: Zapata-Hernández, O., Reyes, L.A., Camurri, C., Carrasco, C., Garza-Montes-de-Oca, N.F., Colás, R. (2015) "Quenching simulation of steel grinding balls". Rev. Metal. 51(3): e049. doi: http://dx.doi. org/10.3989/revmetalm.049.

RESUMEN: Simulación del temple en bolas de desgaste de acero. Las transformaciones de fase en aceros de alto carbono durante su temple y un posterior periodo de estabilización fueron modelizadas por medio del uso de paquetes computacionales basados en el método del elemento finito y de la transformación cinética de los aceros. El modelo se usó para predecir los cambios de temperatura y microestructura que se presentan en bolas de dos diferentes tamaños empleadas en estaciones de molienda de minerales. Se encontró una buena correlación entre las temperaturas medidas mediante la inserción de termopares y aquellas predichas por el modelo una vez que se modificó la conductividad térmica del acero en el intervalo mixto de fases. La predicción de las transformaciones de fase se confirmó a través del análisis metalográfico.

PALABRAS CLAVE: Acero; Microestructura; Modelización por computadora; Tratamiento térmico

Copyright: (C) 2015 CSIC. This is an open-access article distributed under the terms of the Creative Commons Attribution-Non Commercial (by-nc) Spain 3.0 License.

\section{INTRODUCTION}

The processing of mineral ores involves crushing big rocks to reduce them into the fine sizes required for the extraction of the desired minerals; steel balls, bars and rods are used to reduce the rock fragments by impacting and crushing them when being pressed to the walls of the drums during processing.
The pieces (balls, bars or rods) used are heat treated to develop a hard-wear resistant surface to sustain the attrition from the impact and contact with the mineral while maintaining a tough core able to resist the impact between them or with the walls of the drums or with the mineral ore. These pieces have to be continuously replaced as they are consumed by wear, impact or corrosion. Reviews on the causes 
for the consumption of steel during grinding can be found elsewhere (Durman, 1988; Aldrich, 2013).

Steel is heat treated by quenching and tempering to obtain the microstructure required to sustain the working conditions to which the pieces are subjected to. A variety of microstructures can be obtained by changing the heat treatment conditions, the chemical composition or the geometry and size of the piece. The traditional heat treatment process consists in austenitizing the steel at high temperature, to dissolve the alloying elements, followed by immersing the piece into a bath or cooling media, to extract the heat at the desired rate. The piece may remain in the bath until reaching room temperature or can be removed from it. In either case the piece should be tempered in order to reduce the brittleness and crack sensitivity of the steel (Krauss, 2005; Varela et al., 2008). Steel balls used in grinding mills are produced by roll forming and forging and then quenched in warm water and equalized in air to homogenize the temperature within the balls and reduce the residual stresses. The times involved during the quenching and equalizing stages depend upon the size of the ball (Camurri et al., 2008).

The aim of this work is to present the results of the computer simulation of the heat treatment of grinding steel balls of two different sizes that were hot formed and subjected to interrupted quenching and equalized cycles. The materials from which the balls are made are close or above the eutectoid composition, which are not commonly reported in literature. The microstructures present at the end of the treatment were predicted using the kinetic transformation module of proprietary software and confirmed by microstructural analysis.

\section{EXPERIMENTAL PROCEDURE}

The study was made on hot formed steel balls made from high carbon steel bars containing alloying elements such as $\mathrm{Mn}, \mathrm{Cr}, \mathrm{Si}$ and $\mathrm{V}$ to increase hardenability. The chemical composition of the steels was obtained by optical emission spectroscopy and it is shown in Table 1 . The balls were formed at $800^{\circ} \mathrm{C}$, quenched by immersion in water at $50{ }^{\circ} \mathrm{C}$ and then left in still air to equalize their temperatures. Balls of two different sizes were used, the time of quenching and equalization were set as a function of the size, Table 2. The balls of smaller diameter were stored in boxes to allow them to reach room temperature at a slower rate. The larger balls were subjected to tempering that followed a four step cycle described elsewhere (Camurri et al., 2008). The heat treatment is conducted to achieve a minimum hardness (at both surface and bulk) of 60 and 53 Rockwell $\mathrm{C}$ (Table 2). Austenitizing at $800{ }^{\circ} \mathrm{C}$ may result in partial transformation of the steel used in balls $\mathbf{A}$ (98.7\% austenite), as the critical temperature $\left(\mathrm{A}_{\mathrm{cm}}\right)$ of 801.8 and $771.4{ }^{\circ} \mathrm{C}$ for balls $\mathbf{A}$ and $\mathbf{B}$, respectively (Lee and Lee, 2007), the precision of these values are of $\pm 3{ }^{\circ} \mathrm{C}$.

Balls from each diameter were instrumented by inserting type $\mathrm{K}$ thermocouples at their centres and two other radial positions to record the temperature changes during the heat treatment cycle. The thermocouples were connected to a 12 bit analogue to digital logging device with a precision of $\pm 0.7^{\circ} \mathrm{C}$; the accuracy of the thermocouples was of $\pm 1.1^{\circ} \mathrm{C}$. Figure 1 shows in a schematic diagram the positions at which the thermocouples were inserted in either ball. These balls were then sectioned to determine their microstructural components. The samples were polished following standard metallographic techniques and etched with a $2 \%$ solution of nitric acid in ethanol.

The temperature changes were computed using the commercial package DEFORM 2D (Ferguson et al., 2005), the models were constructed taking advantage of the spherical geometry of the pieces, therefore heat transfer was computed in two dimensions as heat is lost only from the external surface and the axis of symmetry correspond to the radius of ball (Fig. 1). The model is able to cope with the complex interactions taking place within the body as the changes in the structural domains are predicted by the continuous cooling diagram computed from

TABLE 1. Chemical composition (wt.\%) of the steel from which the balls were made

\begin{tabular}{lcclcccccc}
\hline Ball & $\mathbf{C}$ & $\mathbf{M n}$ & $\mathbf{P}$ & $\mathbf{S}$ & $\mathbf{S i}$ & $\mathbf{C r}$ & $\mathbf{C u}$ & $\mathbf{T i}$ & $\mathbf{V}$ \\
\hline A & 0.982 & 0.972 & 0.0198 & 0.011 & 0.259 & 0.646 & 0.027 & 0.021 & 0.256 \\
B & 0.736 & 1.004 & 0.010 & 0.018 & 0.311 & 1.030 & 0.019 & 0.023 & 0.005 \\
\hline
\end{tabular}

TABLE 2. Quenching parameters

\begin{tabular}{|c|c|c|c|c|c|c|c|}
\hline \multirow[b]{2}{*}{ Ball } & \multirow{2}{*}{$\begin{array}{l}\text { Diameter } \\
(\mathbf{m m})\end{array}$} & \multirow{2}{*}{$\begin{array}{c}\text { Area } \\
\left(\mathbf{m}^{2}\right)\end{array}$} & \multirow{2}{*}{$\begin{array}{l}\text { Water per } \\
\text { ball (l) }\end{array}$} & \multicolumn{2}{|c|}{ Time (s) } & \multirow{2}{*}{$\begin{array}{c}\text { Water entry } \\
\text { Temperature }\left({ }^{\circ} \mathrm{C}\right)\end{array}$} & \multirow{2}{*}{$\begin{array}{c}\text { Minimum } \\
\text { hardness }(\mathrm{Rc})\end{array}$} \\
\hline & & & & Quenching & Equalizing & & \\
\hline $\mathrm{A}$ & 76.2 (3”) & 0.285 & 4.13 & 80 & 40 & 50 & 60 \\
\hline B & $127.0(5 ")$ & 0.270 & 19.12 & 180 & 120 & 50 & 53 \\
\hline
\end{tabular}




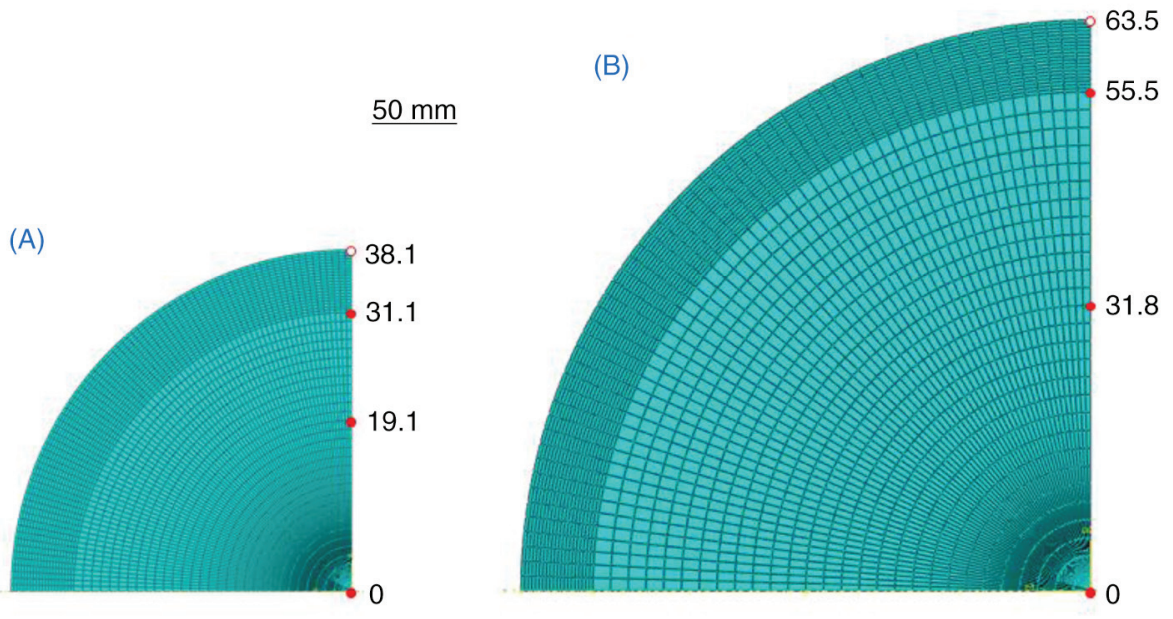

FIGURE 1. Schematic diagram showing the positions of the thermocouples inserted in the steel balls (full circles); an empty circle is shown at the surface.

the JMatPro package (Guo et al., 2013); the thermophysical properties of the material are fed into the finite element model to compute conduction; cooling proceeds applying a heat transfer coefficient at the external surface that depends on temperature. The temperature changes within the body consider the phase transformations occurring during cooling, as the model modifies the properties and characteristics of the material; among the parameters used were the heat capacity, thermal conductivity and density of the different microstructural constituents as a function of temperature.

The elements size used in both balls was refined towards the surface (Fig. 1). The heat transfer coefficients during quenching were derived elsewhere (Camurri et al., 2008) and are shown in Fig. 2. The methodology followed to compute the changes in temperature was similar to that reported elsewhere (Silva et al., 2004; Carlone et al., 2010; Domáski

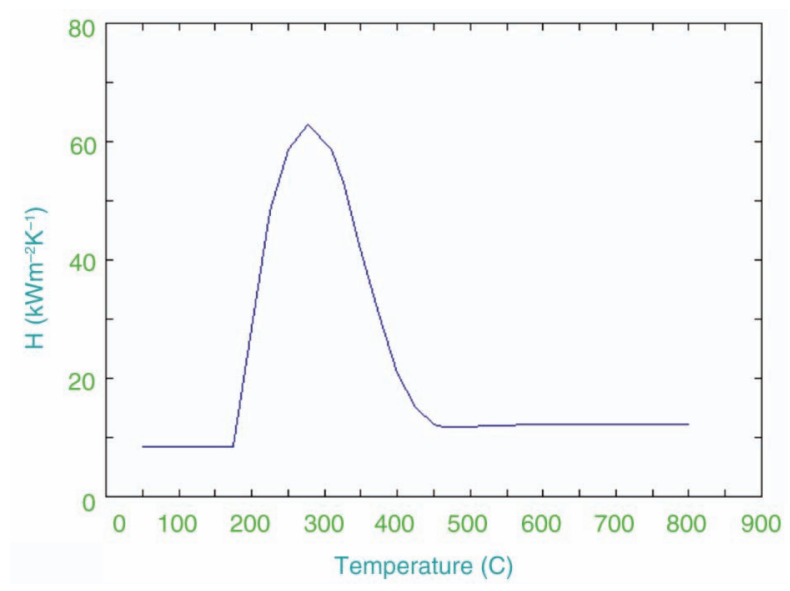

Figure 2. Heat transfer coefficients at a function of surface temperature (Camurri et al., 2008). and Bokota, 2011; Deng and Ju, 2013). Information related to the parameters involved in FEA modelling are shown in Table 3.

\section{RESULTS AND DISCUSSION}

Figure 3 shows a comparison between the measured cooling curves in balls $\mathbf{A}$ and $\mathbf{B}$ (symbols) and the predictions by the finite element models at the corresponding positions and at the surface (full lines). The inset at the upper right corner indicates the positions within the balls. The vertical lines at 80 and 180 seconds (respectively for balls $\mathbf{A}$ and $\mathbf{B}$ ) indicate the times at which the balls were removed from the quenching bath and left to equalize in air. The increment in temperature of the quenching bath as result of the immersion of ball $\mathbf{A}$ can be found in Fig. 4 .

Figure 5 shows the agreement between the temperatures measured by the thermocouples and those predicted by the computer model. Almost all data fall within a $\pm 10 \%$ difference, indicated by the dotted lines in the plot, with the exception of the values recorded by the thermocouple located close to the surface. The readings from the external thermocouple may be caused by the entry of water through the hole drilled to insert the device as the data points fall close to the temperatures predicted at the surface of the balls (Fig. 3).

The agreement between the measured and computed data, shown in Fig. 5, was obtained after using

TABLE 3. Parameters used in the finite element models

\begin{tabular}{lcccccccc}
\hline & \multicolumn{2}{c}{ Number } & & \multicolumn{2}{c}{ Iteration time (s) } & & \multicolumn{2}{c}{ Element size (mm) } \\
\cline { 2 - 3 } Ball & Nodes & Elements & & Quenching & Equalizing & & Smallest & Biggest \\
\hline A & 5259 & 5130 & & 0.10 & 0.10 & & 0.35 & 0.89 \\
B & 2885 & 2799 & & 0.18 & 0.20 & & 1.00 & 2.00 \\
\hline
\end{tabular}




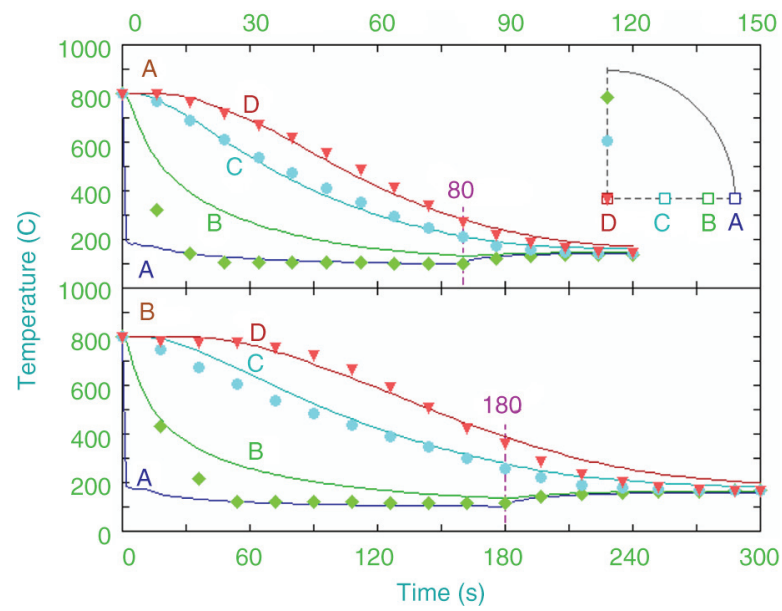

FIGURE 3. Cooling curves obtained from the thermocouples (symbols) and predicted by the FEA model (full lines).

The inset at the upper right corner shows the positions.

the thermophysical properties of the different microstructural components that were computed by the JMatPro software, with the exception of the thermal conductivity of the steel during equalization as the material is made of a varied mixture of austenite and martensite that exhibit different values of thermal conductivity. The values of the thermal conductivity for the different microstructural constituents as a function of temperature obtained from the JMatPro software, together with those used in the simulation of the heat treating of the smaller ball (A) are shown in Fig. 6. It should be mentioned that a series of trials were conducted to obtain the temperature distribution within the balls without taking into consideration the thermophysical properties of the different constituents, but none of these trials offered good results.

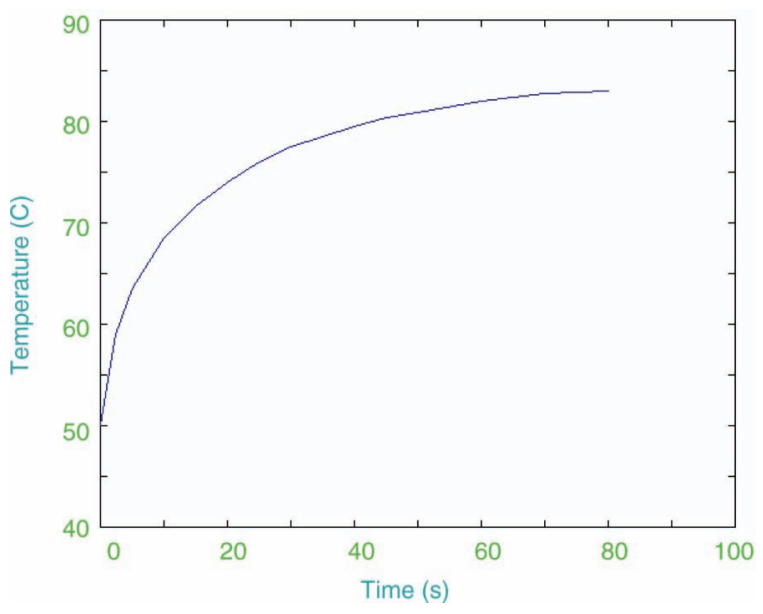

FIGURE 4. Increase in temperature in the bath registered during quenching ball $\mathbf{A}$.

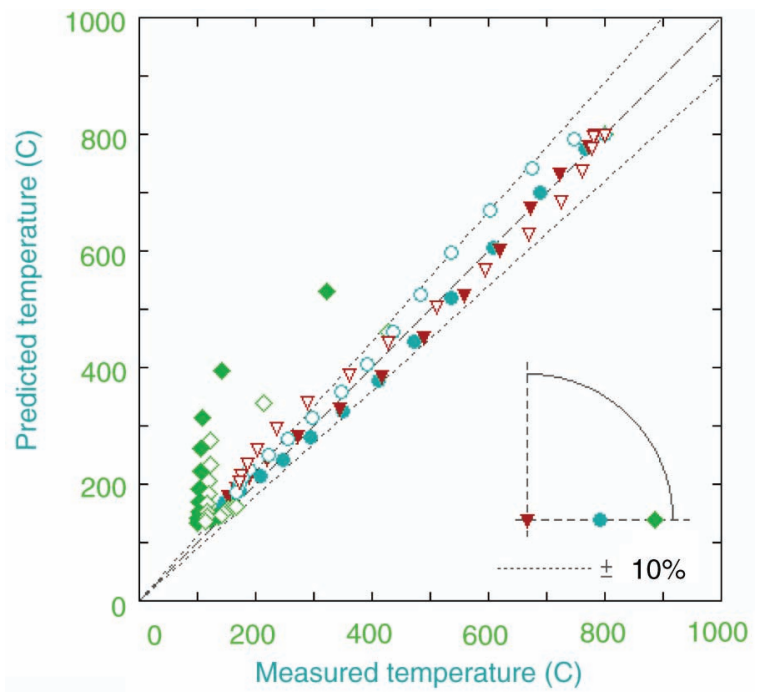

Figure 5. Agreement between the temperatures predicted and measured by the thermocouples in balls $\mathbf{A}$ and $\mathbf{B}$ (full and open symbols respectively).

Figure 7 shows the cooling curves (full lines) for the four positions shown in the right hand side inset, and the critical curves for the continuous cooling transformation (CCT) diagrams predicted by the JMatPro software based on the chemical composition of the steels assuming constant cooling rates, Table 1, assuming an austenite grain size of $40 \mu \mathrm{m}$. It is appreciated in this figure that cooling proceeds through different paths that will result in a range of microstructure mixtures depending on the position within the ball.

The volume fraction of the various microstructural components in balls $\mathbf{A}$ and $\mathbf{B}$ as a function of the radial position and time are shown in Figs. 8 and 9; the distributions during quenching are shown

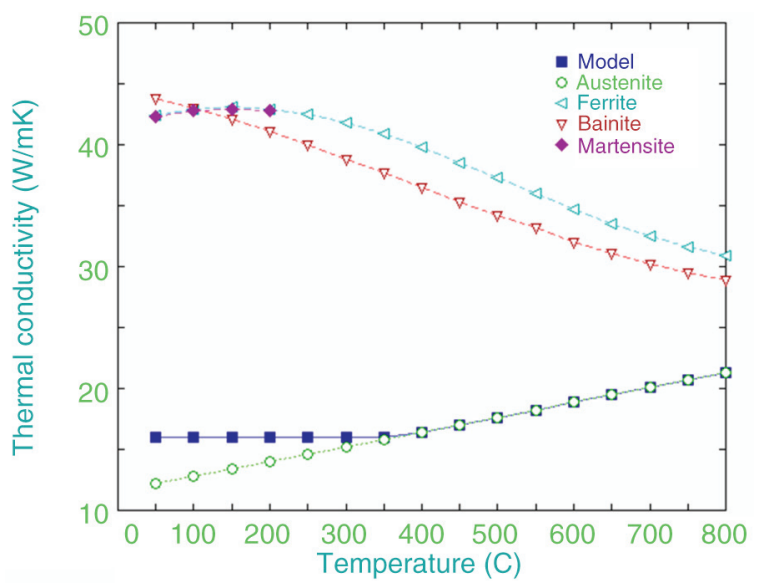

FIgURE 6. Thermal conductivity of the microstructural constituents as a function of temperature (by JMatPro), and the values used to compute the thermal field within ball $\mathbf{A}$. 


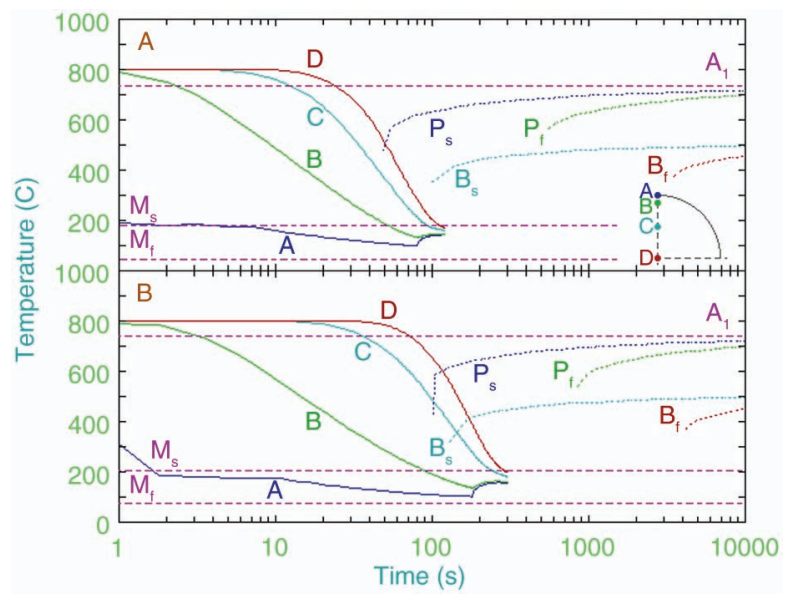

FIGURE 7. Cooling curves predicted by the FEA modelling together with the CCT diagrams for balls $\mathbf{A}$ and $\mathbf{B}$.

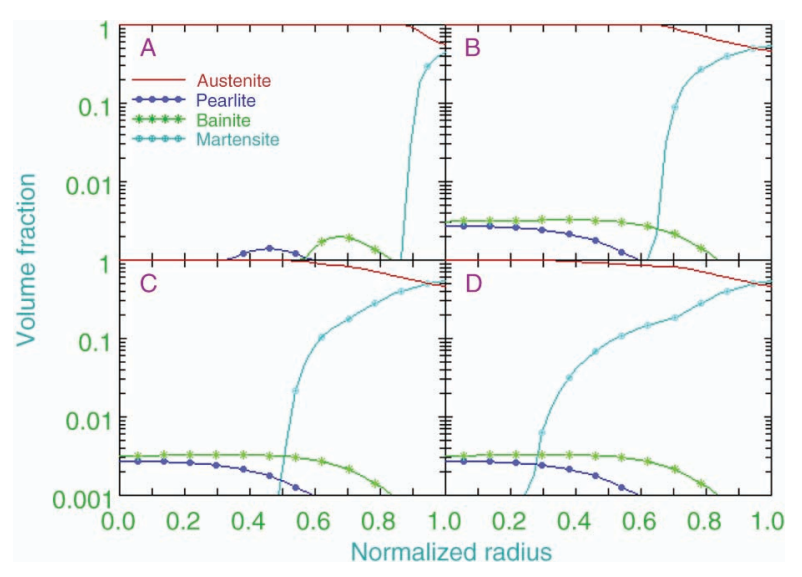

FIGURE 8. Volume fraction of the microstructural constituents as a function of the radial position in ball $\mathrm{A}$ after 40 (A), 80 (B), 100 (C) and 120 (D) seconds.

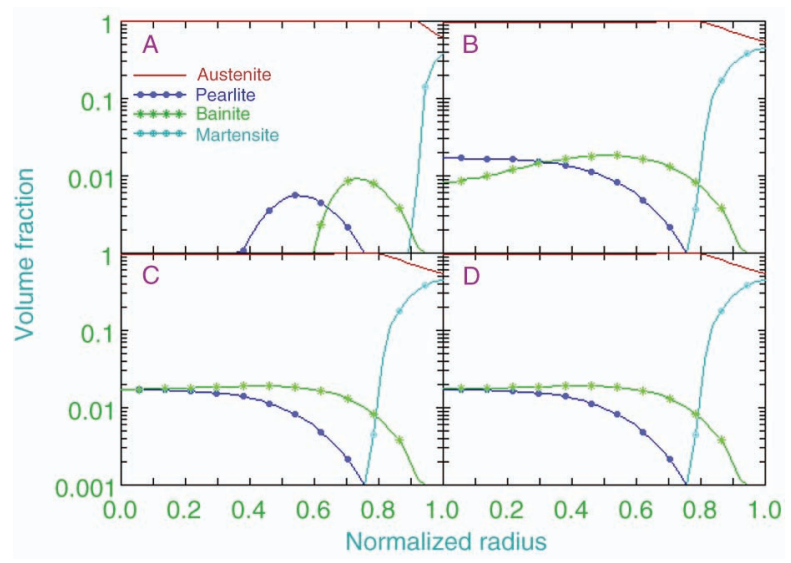

FIGURE 9. Volume fraction of the microstructural constituents as a function of the radial position in ball $\mathbf{B}$ after 90

(A), 180 (B), 240 (C) and 360 (D) seconds.

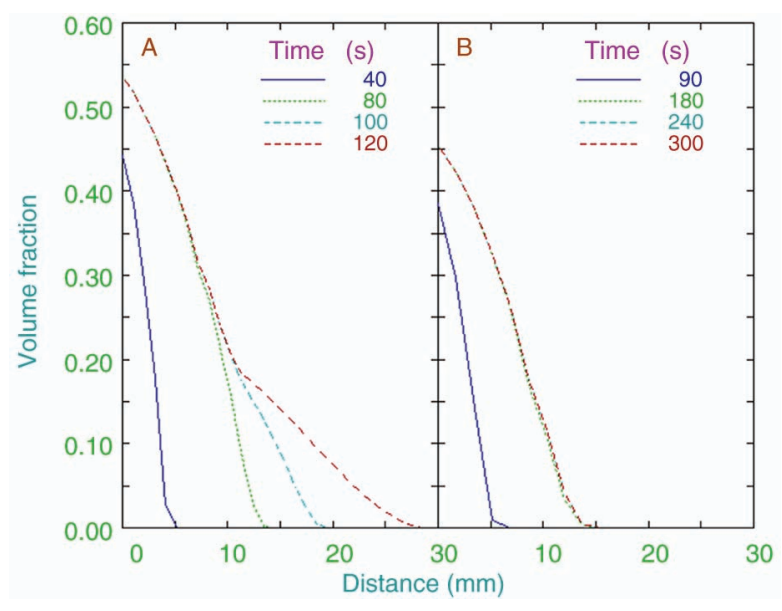

Figure 10. Martensite volume fraction as a function of distance in balls $\mathbf{A}$ and $\mathbf{B}$.

in the upper plots (a) and (b), which correspond to either the middle point and at the end of quenching; the lower plots (c) and (d) show the fractions at the middle point and at the end of equalization. The difference in times elapsed is due to the difference in the quenching and equalizing cycles, see Fig. 3 and Table 2. Figure 10 shows the fraction transformed to martensite in balls $\mathbf{A}$ and $\mathbf{B}$ as a function of distance from the surface. The times were those considered in Figs. 8 and 9. The difference in depth of the transformation to martensite depends on the size of the ball, as the smaller one will be able to cool at a faster rate (Silva et al., 2004; Carlone et al., 2010; Domáski and Bokota, 2011; Deng and Ju, 2013).

The microstructure in the balls was evaluated at the end of the full process, which includes cooling from room temperature after quenching, equalization and self-tempering, as the balls are kept, depending on their sizes, in boxes or within a furnace above room temperature. Figure 11 shows the microstructures that were found at mid-radius in either type of ball. The microstructures in these cases are made of tempered martensite and retained austenite, in ball $\mathbf{A}$, and tempered martensite and bainite in ball $\mathbf{B}$. These observations confirm the predictions from the computer simulation, as it can be seen in Figs. 7 to 10 that the microstructure at the end of quenching and equalizing at mid-radius will be made of martensite and austenite, the later will be able to transform to bainite as the bigger balls are left to cool down to room temperature at a lower rate (Camurri et al., 2008).

\section{CONCLUSIONS}

The use of commercial software based in the finite element analysis and in the kinetic transformation of steels allowed for predicting the behaviour 

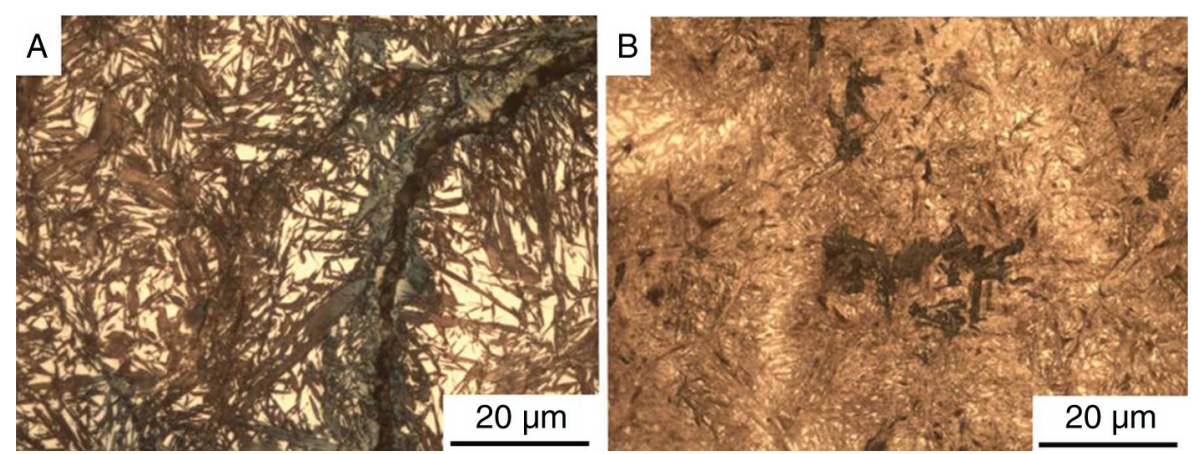

Figure 11. Microstructures found at mid radius in balls $\mathbf{A}$ and $\mathbf{B}$ after quenching and tempering.

during quenching and equalizing of steels balls for grinding mills. The agreement between the predicted and recorded temperatures was considered to be adequate. The conjunction of both packages into a single model predicted the type and distribution of microstructural components at the end of the heat treatment cycles. The various microstructural components were predicted by means of CCT diagrams constructed from the chemical composition and initial microstructure of the steel, this information was used to change the thermophysical properties of the material depending on the nature of the components.

The model predicts partial transformation to martensite at the end of quenching and equalizing; the deep of transformation to martensite will depend on the size of the piece as thinner sections cool at a faster rate. The model can be used to simulate alternative heat treatment cycles to improve the microstructural homogeneity and reduce residual stresses.

\section{ACKNOWLEDGEMENTS}

The authors thank the support of The National Council of Research in Science and Technology of Chile, CONICYT (FONDECYT project $\mathrm{N}^{\circ}$ 1120002), and the National Council for Science and Technology of Mexico, CONACYT.

\section{REFERENCES}

Aldrich, C. (2013). Consumption of steel grinding media in mills A review. Miner. Eng. 49, 77-91. http://dx.doi.org/10.1016/j. mineng.2013.04.023.
Carlone, P., Palazzo, G.S., Pasquino, R. (2010). Finite element analysis of the steel quenching process: Temperature field and solid-solid phase change. Comput. Math. Appl. 59 (1), 585-594. http://dx.doi.org/10.1016/j.camwa.2009.06.006.

Camurri, C., Carrasco, C., Dille, J. (2008). Residual stress during heat treatment of steel grinding balls. J. Mater. Process. Tech. 208 (1-3), 450-456. http://dx.doi.org/10.1016/j. jmatprotec.2008.01.007.

Deng, X., Ju, D. (2013). Modeling and simulation of quenching and tempering process in steels. Phys. Proc. 50, 368-374. http://dx.doi.org/10.1016/j.phpro.2013.11.057.

Domański, T., Bokota, A. (2011). Numerical models of hardening phenomena of tools steel base on the TTT and CCT diagrams. Arch. Metall. Mater. 56 (2), 325-344. http:// dx.doi.org/10.2478/v10172-011-0036-6.

Durman, R.W. (1988). Progress in abrasion-resistant materials for use in comminution processes. Int. J. Miner. Process. 22 (1-4), 381-399. http://dx.doi.org/10.1016/0301-7516(88) 90074-9.

Ferguson, B.L., Li, Z., Freborg, A.M. (2005). Modeling heat treatment of steel parts. Comp. Mater. Sci. 34 (3), 274-281. http://dx.doi.org/1016/j.commatsci.2005.02.005.

Guo, Z., Turner, R., Da Silva, A.D., Sauders, N., Schroeder, F., Cetlin, P.R., Schillé, J.-P. (2013). Introduction of materials modelling into processing simulation. Mater. Sci. Forum 762, 266-276. http://dx.doi.org/10.4028/www.scientific.net/ MSF.762.266.

Krauss, G. (2005). Steels: Processing, structure, and performance, ASM International, Materials Park, Ohio.

Lee, S.J., Lee, Y.K. (2007). Thermodynamic Formula for the $\mathrm{A}_{\mathrm{cm}}$ temperature of low alloy steels. ISIJ Int. 47 (5), 769-771. $\mathrm{http}: / / \mathrm{dx}$.doi.org/10.2355/isijinternational.47.769.

Silva, E.P., Pacheco, P.M.C.L., Savi, M.A. (2004). On the thermomechanical coupling in austenite-martensite phase transformation related to the quenching process. Int. J. Solids Struct. 41 (3-4), 1139-1155. http://dx.doi.org/10.1016/j. ijsolstr.2003.09.049.

Varela, A., García, A., Zaragoza, S., Mier, J.L., Barbadillo, F., García, L. (2008). Influencia de los tratamientos térmicos en el comportamiento frente al desgaste por abrasión de una fundición de grafito esferoidal obtenida mediante adición de boro. Rev. Metal. 44 (4), 293-298. http://dx.doi. org/10.3989/revmetalm.2008.v44.i4.118. 